\section{Atrial Fibrillation: Is it an Additional Risk Factor of Atherosclerosis?}

\section{Olga Germanova ${ }^{1 *}$, Giuseppe Galati ${ }^{2}$, Vladimir Germanov ${ }^{3}$, Inga Prokhorenko ${ }^{4}$ and Andrey Germanov ${ }^{5}$}

${ }^{1}$ Department of Diagnostic Imaging, Samara State Medical University, Samara, Russia

${ }^{2}$ Heart Failure Unit and Division of Cardiology, Cardiothoracic and vascular Department, San Raffaele Hospital and Scientific institute, Milan, Italy

${ }^{3}$ Department of Faculty Surgery, Samara State Medical University, Samara, Russia

${ }^{4}$ Samara Medical University "Reaviz"

${ }^{5}$ Department of Propedeutical therapy, Samara state medical university, Samara, Russia

\begin{abstract}
Aim: To investigate the influence of changes in the parameters of the biomechanics of the heart and the kinetics of the main arteries in different variants of $\mathrm{AF}$ on the development and progression of atherosclerosis.

Materials and Methods: In the study we included 108 patients (66 men and 42 women). The mean age was $67,3 \pm 5,6$ years.In anamnesis, special attention was paid to identifying such diseases as myocardial infarction, stroke, diseases caused by the atherosclerosis of the lower extremities arteries. All patients were performed ECG, 24-hours ECG monitoring, transthoracic and transesophageal echocardiography, the lipids blood analysis. If prescribed, it were performed stress echocardiography with physical exercise or dobutamine. The severity of signs of atherosclerotic lesions of the arteries in all patients was determined by the Doppler ultrasound of the brachiocephalic arteries, branches of the aorta, lower extremities arteries, and renal arteries. According to indications, we performed coronary angiography, renal artery angiography. The biomechanics of the heart and the kinetics of the main arteries were measured by Apexcardiography (ACG) and Sphygmography
\end{abstract}

${ }^{*}$ Corresponding author: Olga Germanova, Department of Diagnostic imaging, Samara State Medical University, Samara, Russia, Tel: +7 9379849880; E-mail: olga_germ@mail.ru

Citation: Germanova O, Galati G, Germanov V, Prokhorenko I, Germanov A (2021) Atrial Fibrillation: Is it an Additional Risk Factor of Atherosclerosis?. J Angiol Vasc Surg 6: 065.

Received: April 19, 2021; Accepted: April 30, 2021; Published: May 07, 2021

Copyright: $\odot 2021$ Germanova O, et al. This is an open-access article distributed under the terms of the Creative Commons Attribution License, which permits unrestricted use, distribution, and reproduction in any medium, provided the original author and source are credited.
(SG) of the main arteries of different types: common carotid and posterior tibial arteries. This method is used more than 100 years and is very informative, non-invasive method highly correlated with intra-vascular pressure and other hemodynamical parameters. According to the 24-hours ECG monitoring, all patients were divided into 3 main groups. This distribution was based on the maximum pause interval between ventricular contractions in AF. The first group included 34 patients in whom the pause between ventricular contractions did not exceed 1 second. The second group included 36 patients in whom the pause between ventricular contractions was 1-2 seconds. The third group included 38 patients in whom the pause between ventricular contractions was more than 2 seconds. Patients of all groups were homogeneous in age, sex, comorbidity.

Results: The incidence of atherosclerotic vascular lesions was higher in group 3 of patients in whom the pause between ventricular contractions in AF exceeded 2 seconds, and the proportion of hemodynamically significant stenoses was also higher in this group.We observed the increase in the main parameters of the heart biomechanics and the kinetics of the main arteries in the first contraction after a long pause between the ventricular contraction in patients with different variants of AF with the following pattern: the longer the pause between the ventricular contraction, the greater the increase in parameters was observed.

Conclusion: $\mathrm{AF}$ is an additional risk factor for the development and progression of atherosclerosis.Places of greatest impact of the first contraction hydraulic shock after a long pause in AF - bifurcation of the common carotid artery, bifurcation of the aorta, large radius of the aortic arch. That is why the atherosclerotic process is localized in these areas. Prognostically more unfavorable in terms of the development and progression of atherosclerosis is the variant of atrial fibrillation with a pause duration between ventricular contractions of more than 2 seconds.

Keywords: Atherosclerosis, Atrial fibrillation; Shock

\section{Introduction}

Atrial Fibrillation (AF) is still one of the most common arrhythmia, leading to the development of numerous complications and patient disability. So, this rhythm disturbance occurs in more than $13 \%$ of the population over 65 years old. The fact is that atrial fibrillation is a risk factor for thromboembolic complications [1-11].

In addition, there is a problem is the prevention and treatment of atherosclerotic lesions of the arterial vessels. Until now, the study and clarification of the pathogenesis and etiological reasons for the development of atherosclerosis continues, the principles of treatment are being adjusted. To date, the monoclonal hypothesis, the lipid hypothesis, and the chronic inflammation hypothesis and others are the leading mechanisms in this process. Also there was evidence of the effect of chronic intoxication with heavy metal vapors (mercury) on endothelial damage and further development and progression of atherosclerosis [12-16]. 
Prevention measures and basic methods of treatment of atherosclerosis have been developed. Nevertheless, the problem of atherosclerosis treatment remains as far from being solved as it was several decades ago. At present, doctors are becoming increasingly frustrated with the insufficient effectiveness of drug therapy for this disease. Despite the conducted multicenter randomized trials, the massive use of statins and other drugs affecting the lipid spectrum, in general, did not justify the hopes placed on them in the prevention and treatment of atherosclerosis.

From his own daily practice, every doctor knows that there is a considerable number of patients who have severe multifocal forms of atherosclerosis with a slightly altered lipid spectrum. And, conversely, there is a sufficient number of patients with pronounced changes in lipid metabolism, but without significant atherosclerotic lesions of the arteries.

Thus, the doctor is obliged to take into account other objective factors that, undoubtedly, contribute to the progressive atherosclerotic lesions of the arteries. First of all, this is a hereditary predisposition to atherosclerosis, the presence of concomitant diseases, such as diabetes mellitus, chronic inflammatory foci in the body, persistent arterial hypertension, the presence of chronic exogenous and endogenous intoxication.

It is impossible to deny the obvious fact that in the first place and to the greatest extent atherosclerotic changes occur in the places of bifurcation and trifurcation of the artery, their mouths and other parts, which are most susceptible to hemodynamic stress. It is noteworthy that these changes occur regardless of the state of lipid metabolism indicators. Therefore, we can reasonably believe that the key moment in the formation of atheroma is initially acute or chronic hydraulic damage to the vascular arterial wall, subsequently triggering a chain of pathogenetic mechanisms leading to atherosclerosis [12-16]. We consider it necessary to investigate one of the factors, which, from our point of view, can reasonably be called the main one.

\section{Aim}

To investigate the influence of changes in the parameters of the biomechanics of the heart and the kinetics of the main arteries in different variants of $\mathrm{AF}$ on the development and progression of atherosclerosis.

\section{Materials and Methods}

In the study we included 108 patients (66 men and 42 women). The mean age was $67,3 \pm 5,6$ years.

Inclusion criteria for the study:

1. Age over 40

2. Permanent AF

3. Signed informed agreement to participate in the study

Exclusion criteria:

1. Persistent arterial hypertension with blood pressure levels exceeding $160 \mathrm{~mm} \mathrm{Hg}$. systolic and $100 \mathrm{~mm} \mathrm{Hg}$ diastolic

2. Diabetes mellitus

3. Family hypercholesterolemia

4. Chronic kidney disease with glomerular filtration rate less than $80 \mathrm{ml} / \mathrm{min}$
5. Chronic heart failure (CHF) more than NYHA III

6. The presence of chronic foci of infection

7. COPD more than moderate severity

8. Hematological diseases associated with hypercoagulation

In anamnesis, special attention was paid to identifying such diseases as myocardial infarction, stroke, diseases caused by the atherosclerosis of the the lower extremities arteries. All patients were performed ECG, 24-hours ECG monitoring, transthoracic and transesophageal echocardiography, the lipids blood analysis. If prescribed, it were performed stress echocardiography with physical exercise or dobutamine.

The severity of signs of atherosclerotic lesions of the arteries in all patients was determined by the Doppler ultrasound of the brachiocephalic arteries, branches of the aorta, lower extremities arteries, and renal arteries. According to indications, we performed coronary angiography, renal artery angiography.

The biomechanics of the heart and the kinetics of the main arteries were measured by Apexcardiography (ACG) and Sphygmography (SG) of the main arteries of different types: common carotid and posterior tibialarteries. This method is used more than 100 years and is very informative, non-invasive method highly correlated with intravascular pressure and other hemodynamical parameters.

To assess changes in the parameters of the biomechanics of the heart and the kinetics of the main arteries, the minimum, average and maximum pause intervals between ventricular contractions during AFwere analyzed. We evaluated the speed, acceleration, power, work of the vascular wall of the arteries.

According to the 24-hours ECG monitoring, all patients were divided into 3 main groups. This distribution was based on the maximum pause interval between ventricular contractions in AF.The first group included 34 patients in whom the pause between ventricular contractions did not exceed 1 second. The second group included 36 patients in whom the pause between ventricular contractions was 1-2 seconds. The third group included 38 patients in whom the pause between ventricular contractions was more than 2 seconds. Patients of all groups were homogeneous in age, sex, comorbidity.

\section{Results}

The examination revealed signs of atherosclerotic lesions of arterial vessels in patients of all three groups. They included stenoses of the brachiocephalic arteries - hemodynamically significant and insignificant, stenoses of the coronary arteries, branches of the aorta, arteries of the lower extremities, and renal arteries.

However, we drew attention to several interesting facts.

Fact 1: The incidence of atherosclerotic vascular lesions was higher in group 3 of patients in whom the pause between ventricular contractions in AF exceeded 2 seconds, and the proportion of hemodynamically significant stenoses was also higher in this group (Table 1). At the same time, at the stage of patient selection, generally recognized risk factors for the development of atherosclerosis were excluded. Is it possible in this situation of the influence of additional, unaccounted risk factor in the development and progression of atherosclerosis? Until now, AF is not among the list of risk factors for the development of atherosclerosis; its gradation has not been made depending on the duration of the pauses between ventricular contractions. 
Citation: Germanova O, Galati G, Germanov V, Prokhorenko I, Germanov A (2021) Atrial Fibrillation: Is it an Additional Risk Factor of Atherosclerosis? J Angiol Vasc Surg 6: 065.

\begin{tabular}{|c|c|c|c|c|}
\hline Parameter & $\begin{array}{c}\text { Group 1 } \\
\text { (N= 34) }\end{array}$ & $\begin{array}{c}\text { Group 2 } \\
\text { (N= 36) }\end{array}$ & $\begin{array}{c}\text { Group 3 } \\
\text { (N = 38) }\end{array}$ & $\mathbf{p}$ \\
\hline $\begin{array}{c}\text { Stenosis of carotid bifurcation } \\
\text { (hemodynamically insignificant) }\end{array}$ & 11 & 13 & 19 & $<0,05$ \\
\hline $\begin{array}{c}\text { Stenosis of carotid bifurcation } \\
\text { (hemodynamically significant) }\end{array}$ & 1 & 2 & 9 & $<0,05$ \\
\hline $\begin{array}{c}\text { Stenoses of the arteries of the lower } \\
\text { extremities (hemodynamically insig- } \\
\text { nificant) }\end{array}$ & 13 & 14 & 22 & $<0,05$ \\
\hline $\begin{array}{c}\text { Stenoses of the arteries of the lower } \\
\text { extremities (hemodynamically sig- } \\
\text { nificant) }\end{array}$ & 1 & 2 & 7 & $<0,05$ \\
\hline $\begin{array}{c}\text { Renal artery stenosis (hemodynamical- } \\
\text { ly significant) }\end{array}$ & 0 & 1 & 4 & $<0,05$ \\
\hline Atherosclerosis of the coronary arteries & 14 & 19 & 33 & $<0,05$ \\
\hline
\end{tabular}

Table 1: Patients in groups 1, 2 and 3.

Fact 2: We observed the increase in the main parameters of the heart biomechanics and the kinetics of the main arteries in the first contraction after a long pause between the ventricular contraction in patients with different variants of $\mathrm{AF}$ with the following pattern: the longer the pause between the ventricular contraction, the greater the increase in parameters was observed (Figures 1-3).

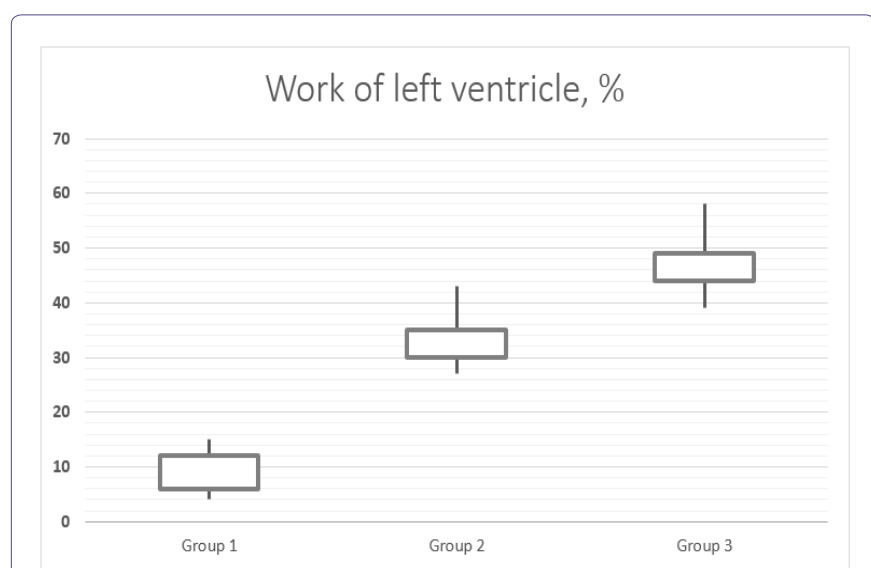

Figure 1: The rise of left ventricle parameter (ACG) - work (in \%) - in each group of the patients after the maximum pause between ventricular contraction in $\mathrm{AF}$.

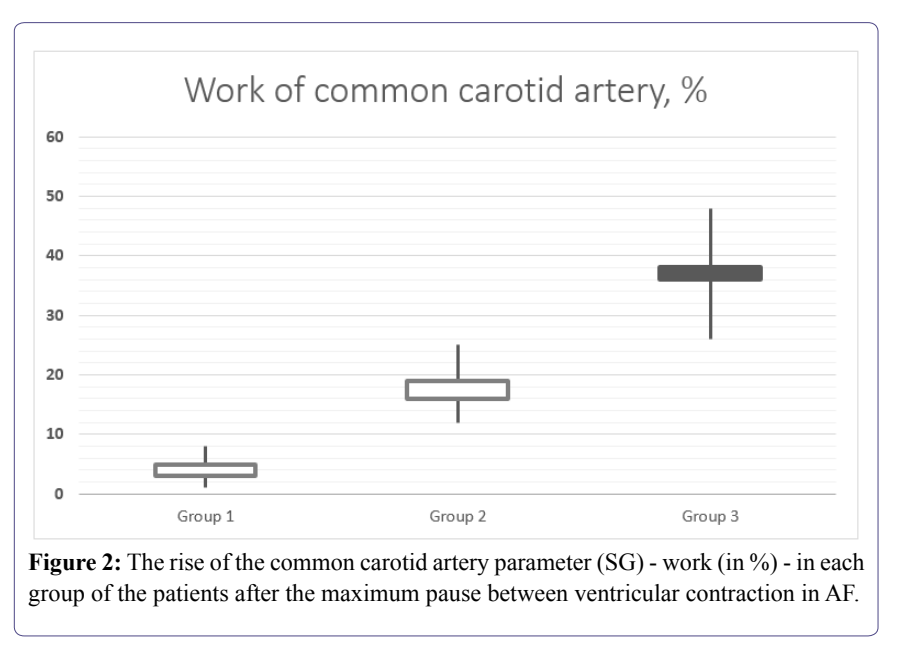

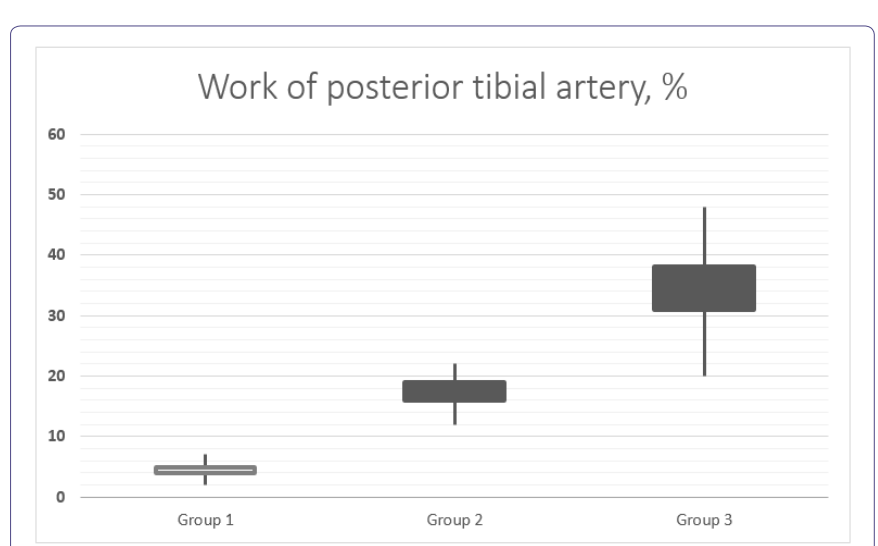

Figure 3: The rise of the posterior tibial artery parameter (SG) - work (in \%) - in each group of the patients after the maximum pause between ventricular contraction in $\mathrm{AF}$.

Thus, the pause between ventricular contractions during AF determines the volume of cardiac output and the degree of participation of the main arteries in the movement of the blood volumestroke.

Summary we can call the increase of all these main heart biomechanical parameters and kinetics of main arteries "hydraulic shock".

\section{Conclusion}

1. $\mathrm{AF}$ is an additional risk factor for the development and progression of atherosclerosis.

2. Hydraulic shockthat appearsduring the passage of a wave after a long pause in AF is a powerful traumatic factor for the intima of the arteries, which, ultimately, can lead to the formation of an atherosclerotic process. The presence of a hydraulic shock in AF determines the statement "atheroma builds itself". This mechanism is universal for various rhythm disturbances, in particular, extrasystolic arrhythmias, which was the subject of our separate study $[17,18]$.

3. Places of greatest impact of the first contraction hydraulic shock after a long pause in AF - bifurcation of the common carotid artery, bifurcation of the aorta, large radius of the aortic arch. That is why the atherosclerotic process is localized in these areas.

4. Prognostically more unfavorable in terms of the development and progression of atherosclerosis is the variant of atrial fibrillation with a pause duration between ventricular contractions of more than 2 seconds.

\section{References}

1. Chugh SS, Havmoeller R, Narayanan K, Singh D, Rienstra M, et al. (2014) Worldwide epidemiology of atrial fibrillation: a Global Burden of Disease 2010 Study. Circulation 129: 837-847.

2. Krijthe BP, Kunst A, Benjamin EJ, Lip GY, Franco OH, et al. (2013) Projections on the number of individuals with atrial fibrillation in the European Union, from 2000 to 2060. Eur Heart J 34: 2746-2751.

3. Colilla S, Crow A, Petkun W, Singer DE, Simon T, et al. (2013) Estimates of current and future incidence and prevalence of atrial fibrillation in the U.S. adult population. Am J Cardiol 112: 1142-1147.

4. Staerk L, Sherer JA, Ko D, Benjamin EJ, Helm RH (2017) Atrial fibrillation: epidemiology, pathophysiology, and clinical outcomes. CircRes 120: 1501-1517. 
Citation: Germanova O, Galati G, Germanov V, Prokhorenko I, Germanov A (2021) Atrial Fibrillation: Is it an Additional Risk Factor of Atherosclerosis?. J Angiol Vasc Surg 6: 065.

5. Hindricks G, Potpara T, Dagres N, Arbelo E, Bax JJ, et al. (2021) 2020 ESC Guidelines for the diagnosis and management of atrial fibrillation developed in collaboration with the European Association for Cardio-Thoracic Surgery (EACTS): The Task Force for the diagnosis and management of atrial fibrillation of the European Society of Cardiology (ESC) Developed with the special contribution of the European Heart Rhythm Association (EHRA) of the ESC. European Heart Journal 42: 373-498.

6. Ceornodolea AD, Bal R, Severens JL (2017) Epidemiology and management of atrial fibrillation and stroke: review of data from four European countries. Stroke Res Treat 2017: 8593207.

7. Pistoia F, Sacco S, Tiseo C, Degan D, Ornello R, et al. (2016) The epidemiology of atrial fibrillation and stroke. CardiolClin 34: 255-268.

8. Andrew NE, Thrift AG, Cadilhac DA (2013) The prevalence, impact and economic implications of atrial fibrillation in stroke: what progress has been made? Neuroepidemiology 40: 227-239.

9. Lin HJ, Wolf PA, Kelly-Hayes M, Beiser AS, Kase CS, et al. (1996) Stroke severity in atrial fibrillation. The Framingham Study. Stroke 27: 17601764.

10. Meyre P, Blum S, Berger S, Aeschbacher S, Schoepfer H, et al. (2019) Risk of hospital admissions in patients with atrial fibrillation: a systematic review and meta-analysis. Can J Cardiol 35: 1332-1343.

11. Wang TJ, Massaro JM, Levy D, Vasan RS, Wolf PA, et al. (2003) A risk score for predicting stroke or death in individuals with new-onset atrial fibrillation in the community: the Framingham Heart Study. JAMA 290: 1049-1056.
12. Palinski W, Tsimikas S (2002) Immunomodulatory effects of statins: Mechanisms and potential impact on arteriosclerosis. J Am Soc Nephrol 13: $1673-1681$.

13. Whelton SP, Deal JA, Zikusoka M, Jacobson LP, Sarkar S, et al. (2019) Associations between lipids and subclinical coronary atherosclerosis. AIDS 33: 1053-1061

14. Xu Q (2003) Infections, heat shock proteins, and atherosclerosis. Curr Opin Cardiol 18: 245-252

15. Koichi S, Aikawa M, Takayama K, Libby P, Mitchell RN (2003) Direct Anti-Inflammatory Mechanisms Contribute to Attenuation of Experimental Allograft Arteriosclerosis by StatinsCirculation. - 2003. 108: 21132120 .

16. Kamanna VS, Ganji SH, Kashyap MI (2013) Myeloperoxidase and atherosclerosis. Curr Cardiovaskular Ris 7: 142-167.

17. Germanova O, Shchukin Y, Germanov V, Galati G, Germanov A (2021) Extrasystolic arrhythmia: is it an additional risk factor of atherosclerosis? Minerva Cardioangiol.

18. Germanova OA, Kryukov NN, Germanov AV (2018) Is extrasystolic arrhythmia the risk factor of arterial thromboembolism? /ACCA Congress, Milan, Page no: 495 


\section{Hit \\ нвам}

Advances In Industrial Biotechnology | ISSN: 2639-5665

Advances In Microbiology Research | ISSN: 2689-694X

Archives Of Surgery And Surgical Education | ISSN: 2689-3126

Archives Of Urology

Archives Of Zoological Studies | ISSN: 2640-7779

Current Trends Medical And Biological Engineering

International Journal Of Case Reports And Therapeutic Studies | ISSN: 2689-310X

Journal Of Addiction \& Addictive Disorders | ISSN: 2578-7276

Journal Of Agronomy \& Agricultural Science | ISSN: 2689-8292

Journal Of AIDS Clinical Research \& STDs | ISSN: 2572-7370

Journal Of Alcoholism Drug Abuse \& Substance Dependence | ISSN: 2572-9594

Journal Of Allergy Disorders \& Therapy | ISSN: 2470-749X

Journal Of Alternative Complementary \& Integrative Medicine | ISSN: 2470-7562

Journal Of Alzheimers \& Neurodegenerative Diseases | ISSN: 2572-9608

Journal Of Anesthesia \& Clinical Care | ISSN: 2378-8879

Journal Of Angiology \& Vascular Surgery | ISSN: 2572-7397

Journal Of Animal Research \& Veterinary Science | ISSN: 2639-3751

Journal Of Aquaculture \& Fisheries | ISSN: 2576-5523

Journal Of Atmospheric \& Earth Sciences | ISSN: 2689-8780

Journal Of Biotech Research \& Biochemistry

Journal Of Brain \& Neuroscience Research

Journal Of Cancer Biology \& Treatment | ISSN: 2470-7546

Journal Of Cardiology Study \& Research | ISSN: 2640-768X

Journal Of Cell Biology \& Cell Metabolism | ISSN: 2381-1943

Journal Of Clinical Dermatology \& Therapy | ISSN: 2378-8771

Journal Of Clinical Immunology \& Immunotherapy | ISSN: 2378-8844

Journal Of Clinical Studies \& Medical Case Reports | ISSN: 2378-8801

Journal Of Community Medicine \& Public Health Care | ISSN: 2381-1978

Journal Of Cytology \& Tissue Biology | ISSN: 2378-9107

Journal Of Dairy Research \& Technology | ISSN: 2688-9315

Journal Of Dentistry Oral Health \& Cosmesis | ISSN: 2473-6783

Journal Of Diabetes \& Metabolic Disorders | ISSN: 2381-201X

Journal Of Emergency Medicine Trauma \& Surgical Care | ISSN: 2378-8798

Journal Of Environmental Science Current Research | ISSN: 2643-5020

Journal Of Food Science \& Nutrition | ISSN: 2470-1076

Journal Of Forensic Legal \& Investigative Sciences | ISSN: 2473-733X

Journal Of Gastroenterology \& Hepatology Research | ISSN: 2574-2566
Journal Of Genetics \& Genomic Sciences | ISSN: 2574-2485

Journal Of Gerontology \& Geriatric Medicine | ISSN: 2381-8662

Journal Of Hematology Blood Transfusion \& Disorders | ISSN: 2572-2999

Journal Of Hospice \& Palliative Medical Care

Journal Of Human Endocrinology | ISSN: 2572-9640

Journal Of Infectious \& Non Infectious Diseases | ISSN: 2381-8654

Journal Of Internal Medicine \& Primary Healthcare | ISSN: 2574-2493

Journal Of Light \& Laser Current Trends

Journal Of Medicine Study \& Research | ISSN: 2639-5657

Journal Of Modern Chemical Sciences

Journal Of Nanotechnology Nanomedicine \& Nanobiotechnology | ISSN: 2381-2044

Journal Of Neonatology \& Clinical Pediatrics | ISSN: 2378-878X

Journal Of Nephrology \& Renal Therapy | ISSN: 2473-7313

Journal Of Non Invasive Vascular Investigation | ISSN: 2572-7400

Journal Of Nuclear Medicine Radiology \& Radiation Therapy | ISSN: 2572-7419

Journal Of Obesity \& Weight Loss | ISSN: 2473-7372

Journal Of Ophthalmology \& Clinical Research | ISSN: 2378-8887

Journal Of Orthopedic Research \& Physiotherapy | ISSN: 2381-2052

Journal Of Otolaryngology Head \& Neck Surgery | ISSN: 2573-010X

Journal Of Pathology Clinical \& Medical Research

Journal Of Pharmacology Pharmaceutics \& Pharmacovigilance | ISSN: 2639-5649

Journal Of Physical Medicine Rehabilitation \& Disabilities | ISSN: 2381-8670

Journal Of Plant Science Current Research | ISSN: 2639-3743

Journal Of Practical \& Professional Nursing | ISSN: 2639-5681

Journal Of Protein Research \& Bioinformatics

Journal Of Psychiatry Depression \& Anxiety | ISSN: 2573-0150

Journal Of Pulmonary Medicine \& Respiratory Research | ISSN: 2573-0177

Journal Of Reproductive Medicine Gynaecology \& Obstetrics | ISSN: 2574-2574

Journal Of Stem Cells Research Development \& Therapy | ISSN: 2381-2060

Journal Of Surgery Current Trends \& Innovations | ISSN: 2578-7284

Journal Of Toxicology Current Research | ISSN: 2639-3735

Journal Of Translational Science And Research

Journal Of Vaccines Research \& Vaccination | ISSN: 2573-0193

Journal Of Virology \& Antivirals

Sports Medicine And Injury Care Journal | ISSN: 2689-8829

Trends In Anatomy \& Physiology | ISSN: 2640-7752

Submit Your Manuscript: https://www.heraldopenaccess.us/submit-manuscript 